stimulants increased 2.9-fold (2.6-fold for MPH). (Robison LM, Sclar DA, Skaer TL, Galin RS. National trends in the prevalence of attention-deficit/hyperactivity disorder and the prescribing of methylphenidate among school-age children: 1990-1995. Clin Pediatr April 1999;38:209-217). (Reprints: Linda M Robison MSPH, Pharmacoeconomics \& Pharmacoepidemiology Research Unit, College of Pharmacy, Washington State University, PO Box 646510, Pullman, WA 99164).

COMMENT. A 2.3-fold increase in the prevalence of the ADHD diagnosis in children and 2.6-fold increase in MPH prescriptions in the period 1990-1995 are partially explained by the increase in diagnosis of the syndrome in girls and the increasing age of patients treated in the US. One third of ADHD cases diagnosed during childhood still meet the diagnostic criteria in adulthood, according to Swanson JM et al. (Lancet 1998;351:429-433). In some centers, medication is continued through adolescence into early adulthood, contributing to the reports of an increased prevalence rate. (Safer DJ, Krager JM. Pediatrics 1994;94:462-464).

A 1995 survey of pediatric neurologists regarding usage of stimulant medication for ADHD showed that, in this specialty, treatment was continued for a mean of 3.5 years, with a range of 1 to 5 years. Of patients treated, $70 \%$ were $6-12$ years of age, and only $20 \%$ were $13-18$ years. (Millichap JG. Ped Neur Briefs Sept 1996;10:65).

\title{
RITALIN AND ADDERAL COMPARISON IN ADHD
}

A double-blind, crossover, 6 week study at the Departments of Psychology and Psychiatry, State University of New York at Buffalo, compared the efficacy and time-course of Ritalin ${ }^{\circledR}\left(10 \mathrm{mg}\right.$ and $17.5 \mathrm{mg}$ bid), Adderal ${ }^{\circledR}(7.5 \mathrm{mg}$ and 12.5 $\mathrm{mg}$ ), and placebo in 25 ADHD children, mean age 9.6 years. A beneficial response in behavior and academic productivity was obtained with both drugs in $75 \%$ of participants. The effects of the two drugs were similar, except that Adderal may be more potent and effects may persist for an hour or two longer than Ritalin. The midday doses of both drugs appear to be more effective than the morning doses, suggesting an additive effect, and an indication for using a relatively lower dose at lunch-time. Side effects were not significantly different for Ritalin and Adderal, although the reported incidence of tics, dysphoria, sleep disturbance, and loss of appetite was greater for Adderal. (Pelham WE, Aronoff HR, Midlam JK et al. A comparison of Ritalin and Adderal: efficacy and time-course in children with attention-deficit/hyperactivity disorder. Pediatrics April 1999;103: www.pediatrics.org/cgi/ content/full/103/4/43). (Reprints: William E Pelham PhD, Department of Psychology, Park Hall, SUNY at Buffalo, Buffalo, NY 14260).

COMMENT. Adderal may offer a useful addition to the psychostimulant armamentarium for treatment of ADHD. It may be substituted for methylphenidate (MPH) when a longer acting drug is required, if MPH rebound symptoms are troublesome, and when children object to receiving midday doses at school. Its superiority to Dexedrine has not been established, and both amphetamines have the disadvantage of mandatory triplicate prescriptions.

Methylphenidate versus dextroamphetamine in ADHD. Efron D, commenting on the Adderal study by Swanson et al (1998), refers to his experience and comparative trials of MPH and dextroamphetamine in 125 children with ADHD, at the Royal Children's Hospital, Melbourne, Australia. (L Am Acad Child Adolesc Psychiatry May 1999;38:500). With dosages standardized at 0.15 $\mathrm{mg} / \mathrm{kg} / \mathrm{bid}$ for dextroamphetamine and $0.3 \mathrm{mg} / \mathrm{kg} / \mathrm{bid}$ for $\mathrm{MPH}$, beneficial effects were similar, though consistently favoring MPH. The incidence and severity of 
side effects were significantly greater with dextroamphetamine, particularly insomnia, irritability, crying, anxiousness, dysphoria, and nightmares. Dextroamphetamine is the preferred first-line stimulant for ADHD in Australia because of cost constraints. However, this study demonstrates the superiority of methylphenidate over an amphetamine, and in the US, MPH should be the drug of choice. Dextroamphetamine and Adderal are alternative therapies of proven value.

Short- and long-term safety and efficacy of stimulants in ADHD is reviewed by Greenhill LL et al. (I Am Acad Child Adolesc Psychiatry May 1999;38:503-512). Long-term use of stimulants is not considered harmful.

\section{NEUROCOGNITIVE DEFICITS IN ADOLESCENTS BORN PRETERM}

Neurocognitive and behavioral outcome at adolescence of 105 infants born very preterm ( $<33$ weeks) was studied and correlated with neonatal ultrasonographic scans and MRI at age 14-15 years, at University College London Medical School, UK. Of 72 cases completing the study, 40 had abnormal and 15 equivocal MRIs, markers of hypoxic-ischemic damage, especially ventricular dilatation, atrophy of the corpus callosum - predominantly posterior, and white matter abnormalities. In contrast, of 21 controls, one had abnormal and 5 equivocal MRI. MRI detected more abnormalities than neonatal ultrasonography (40 of 72 vs 31 of 72). Tests of functional neurodevelopment and behavior at age 14-15 years showed significantly more reading, adjustment, and neurological impairments in the preterm cases than controls, but only the impaired behavior on the Rutter scale was significantly related to structural brain abnormalities on MRI. Four cases and no controls had epilepsy, and all four had abnormal MRI scans. (Stewart AL, Rifkin L, Amess PN et al. Brain structure and neurocognitive and behavioral function in adolescents who were born very preterm. Lancet May 15 1999;353:1653-57). (Respond: Dr AL Stewart, Perinatal Brain Research Group, Department of Paediatrics, Rayne Institute, University College London Medical School, London WC1E 6JJ, UK).

COMMENT. Very preterm infants are at high risk of neurocognitive and behavioral problems and MRI abnormalities in adolescence, and abnormalities in the MRI, notably in the corpus callosum, are significantly correlated with neurobehavioral disorders. MRI identifies more brain lesions than does neonatal ultrasonography.

Callosal and cortical contribution to procedural learning has been studied in eleven adult patients, 6 acallosal and 5 callosotomized, at the University of Montreal, Canada. (de Guise E, del Pesce M, Foschi N et al. Brain June 1999;122:1049-1062). Epileptic foci in frontal or temporal areas occurred in 7 and post-surgical bilateral prefrontal atrophy in one. Performance of a serial reaction time task, involving bimanual or unimanual key-pressing responses to a sequence of repeated visual stimuli, showed that the anterior part of the corpus callosum is crucial for integration and transfer of a procedural visuomotor skill, and the frontal lobes are important for unilateral procedural learning. Acallosal subjects have explicit knowledge of the procedure but are incapable of learning the skill implicitly when interhemispheric integration is required. In agenesis of the corpus callosum subjects, there is a disconnection deficit and a dissociation of declarative (explicit) and procedural (implicit) memory.

Visuomotor learning, a procedural memory task, refers to a motor skill or cognitive routine acquired through practice. This type of implicit memory, 